\title{
Behaviour and Social Evolution of Wasps: The Communal Aggregation Hypothesis.
}

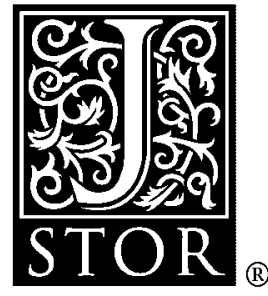

\author{
Review Author[s]: \\ Raghavendra Gadagkar
}

The Quarterly Review of Biology, Vol. 69, No. 4. (Dec., 1994), pp. 558-559.

Stable URL:

http://links.jstor.org/sici?sici=0033-5770\%28199412\%2969\%3A4\%3C558\%3ABASEOW\%3E2.0.CO\%3B2-Z

The Quarterly Review of Biology is currently published by The University of Chicago Press.

Your use of the JSTOR archive indicates your acceptance of JSTOR's Terms and Conditions of Use, available at http://www.jstor.org/about/terms.html. JSTOR's Terms and Conditions of Use provides, in part, that unless you have obtained prior permission, you may not download an entire issue of a journal or multiple copies of articles, and you may use content in the JSTOR archive only for your personal, non-commercial use.

Please contact the publisher regarding any further use of this work. Publisher contact information may be obtained at http://www.jstor.org/journals/ucpress.html.

Each copy of any part of a JSTOR transmission must contain the same copyright notice that appears on the screen or printed page of such transmission.

JSTOR is an independent not-for-profit organization dedicated to creating and preserving a digital archive of scholarly journals. For more information regarding JSTOR, please contact support@jstor.org. 
Why then are the other chapters a disappointment? It is not because of the authors; they are all experts on the various groups. The analysis has gone farther for insects than for other groups. Either insects have been easier to work with, or more talented folk have worked on them. This should pose a challenge to researchers on other groups! Finally, even in a 390-page book there is simply not sufficient space to describe all the interesting research on homing. Even the bibliography the book provides is not as comprehensive as one would like, although it should be very useful as a means for getting started. Overall, this is likely to be a useful book for students, but with the exception of the chapter on arthropods, it is not a major scholarly contribution.

Charles Walcott, Cornell Laboratory of Ornithology, Ithaca, New York

Perspectives in Ethology. Volume 10: Behavior and Evolution.

Edited by P. P. G. Bateson, Peter H. Klopfer, and Nicholas S. Thompson. Plenum Press, New York. $\$ 75.00$. xvi + 285 p.; ill.; index. ISBN: 0-30644398-8. 1993.

The stated theme of this volume is sameness and difference at the levels of the individual, the population, and the species. A theme this broad is no theme at all and the volume is more properly regarded as a collection of review articles that span the length and breadth of ethology. Nevertheless, the specific topics are interesting, their quality is generally high, and some themes do emerge, although not by design.

Several articles address the interaction between natural selection and the constraining forces of physiology, genetics, development, and phylogeny. Glickman et al. review the costs and benefits of androgenization in the female spotted hyena, whose false penis was used as an example in Gould and Lewontin's influential Spandrels paper ("The spandrels of San Marco and the Panglossian paradigm: a critique of the adaptationist programme" in The Evolution of Adaptation by Natural Selection, The Royal Society, London, 1979). Csányi reviews his own laboratory's extensive research on behavior, learning and genetics in the Paradise fish. Kappeler reviews female dominance in mammals, which seems to have a strong phylogenic contraint (especially common in lemurs).

Several other articles address complex interactions among individuals or components of a behavioral system that lead to emergent properties. Nowicki and Podos emphasize levels of complexity in the production of birdsong; Smillie attempts to develop a concept of social environments; Johnson examines animal communication from the standpoint of cognitive psychology; and Laland et al. sketch a theoretical framework for studying animal social learning. Barker provides an elegant account of recent research on seemingly Larmarkian evolution that shows how philosophers can help clarify conceptual issues in biology.

Series such as this can succeed by devoting volumes to a single unified theme or by providing a forum for thoughtful essays on a wide range of topics. Volume 10 succeeds in the latter sense, and many of the articles deserve to be widely read by ethologists.

David Sloan Wilson, Biological Sciences, Binghamton University, Binghamton, New York

Behaviour and Social Evolution of Wasps: The Communal Aggregation Hypothesis. Oxford Series in Ecology and Evolution.

By Yosiaki Itố; Series Editors: Robert M. May and Paul H. Harvey. Oxford University Press, Oxford and New York. $\$ 52.00$ (hardcover); $\$ 24.95$ (paper). viii +159 p.; ill.; author index, index of scientific names, and subject index. ISBN: 0-19-854683-1 (hc); 0-19-854046-9 (pb). 1993.

Social insects evoke an enduring fascination in humans for several reasons. To the layperson it is their striking similarity to human societies and their remarkable efficiency and organization that have an almost emotional appeal. To evolutionary biologists, even more striking is the altruism so often exhibited by workers in social insect colonies. Understanding the evolution of altruistic workers who, within the framework of natural selection, give up personal reproduction and work to rear the offspring of another individual, has been a fascinating preoccupation. Social wasps, especially the so-called primitively eusocial wasps, are particularly well suited as model systems for this endeavor. Among their many useful characters, perhaps the most important is that many if not all individuals in these species appear to retain the options of "selfish" direct reproduction and "altruistic" helping behavior. A variety of genera and species of these social wasps have been the subjects of intense observational, experimental, and theoretical investigations.

The author of the book under review has played a significant role in this activity during the past 15 years. He has traveled widely in Japan, Panama, and Australia to observe and document the behavior of more species of social wasps than almost anyone else I know. He is therefore in a unique position to draw upon his experiences from diverse species and habitats to bear on the question of social evolution of wasps. That is the aim of this book, and he partially succeeds in achieving it. 
The book itself is largely a collation of his numerous papers, but it is held together, to some extent, by four introductory chapters and three concluding chapters. The remaining six chapters deal with specific issues such as dominance relations and multiple queens or with specific species such as Ropalidia fasciata and Polistes canadensis. Itô's main conclusion is that, although "Kin-selection/inclusive fitness theory has created a new era in understanding the evolution of insect sociality . . . the one sided view of kin-selection has also set a constraint on further studies. We can generate many new study projects by liberating ourselves from this view."

The main argument of the so-called kin-selection/inclusive fitness theory is that an altruistic trait could spread by natural selection if the benefit of the altruism (measured as the number of relatives reared) multiplied by the genetic relatedness between the altruist and the relatives reared, is greater than the cost of altruism (measured by the number of offspring given up by the altruist) multiplied by the altruist's genetic relatedness to his or her offspring. What Itô means by a one-sided view of kin selection is the excessive concentration on above inequality being brought about by the inequalities in the genetic relatedness terms and relatively less attention to the possible role of inequalities in the cost and benefit terms.

To a large extent Itô's critical conclusion is justified, but things are changing rapidly and far more attention is being paid in recent times to measuring costs and benefits of altruism, thanks to the repeated warnings by Itô and a large number of other social insect researchers.

The book under review, however, is not without its faults. It is too much of a collection of papers; there has not been sufficient attempt to make it read like a book. Even though the publication date is 1993, the book does not pay sufficient attention to a number of recent theoretical developments in the field. There are also several problems with terminology and interpretations of the literature. The most serious problem with terminology is the inconsistent way in which the terms haplometrosis and pleometrosis are used, sometimes to refer to single and multiple egg layers, respectively, and sometimes to refer to single and multiple foundress associations, respectively. An example of inaccurate interpretation of the literature is seen when Itô uses a 1988 paper by Frumhoff and Baker to support his contention that kin-recognition abilities are well developed, but ignores a series of criticisms of that conclusion that appeared in the same journal in 1990.

In my opinion, a serious shortcoming of this book is the lack of careful copy editing, which could have greatly improved the text in many places.
Much more serious is the fact that some of the figures and tables are almost completely unintelligible. Figures 7.2 to 7.5 and 13.1 to 13.2 are glaring examples of what should not get past any copy editor. Given that the author is not a native English speaker and that this book is the result of his own efforts to translate a previous version published in Japanese, the blame falls more heavily on the copy editor and publisher.

RAghavendRa GADAGKar, Ecological Sciences, Jawaharlal Nehru Centre for Advanced Scientific Research, Indian Institute of Science, Bangalore, India

The Encyglopedia of Land Invertebrate BeHAVIOUR.

By Rod Preston-Mafham and Ken Preston-Mafham.

The MIT Press, Cambridge (Massachusetts). $\$ 45.00$.

320 p.; ill.; indexes of scientific names and common names, and general index. ISBN: 0-26216137-0. 1993.

Most professional biologists find both visual and intellectual beauty in the study of nature, and I think many of us would admit that this beauty is a substantial part of our motivation. We seldom succeed in simultaneously communicating, however, the excitement of visual and intellectual beauty to nonspecialists. I think this book is as successful an attempt to do this as I have seen.

The book combines coffee-table-quality color photographs, often of exotic (and identified!) tropical species, with an easy-to-read text that quickly plunges into such esoteric topics as sperm precedence, operational sex ratios, and resource defense polygyny. Many of the photos are not just portraits of animals at rest, but illustrate unexpected, refined ways of making a living (e.g., a view of ants tending homopterans is enlivened by a mosquito robbing honeydew from the mouth of a worker). The beautiful photographs, and the easy access to the text, which includes long figure captions and boxes describing particular stories, are in the style of a coffee-table nature book. But the text is not. The authors have perused a lot of recent literature, and in general they describe correctly the stories familiar to a specialist, plus some that were new and interesting to me. In places they also present original interpretations of their own (e.g., to explain the elaborate courtship rituals in spiders), marshalling data and arguments to support their views. The intellectual as well as the visual excitement of studying arthropod behavior comes through.

This is not to say that I did not have reservations. The coverage of many groups other than insects and spiders (e.g., mites) is poor for a book that pretends to be "encyclopedic." The imbalance between the different topics (134 pages for sexual 